\title{
Frequency of Lumbago and its Risk Factors among Medical Students of Fatima Memorial Hospital College of Medicine \& Dentistry Lahore
}

\author{
Fahad Tanveer ${ }^{1}$, Sana Shahid ${ }^{2}$ \\ ${ }^{1}$ Senior Lecturer, Fatima Memorial Hospital College of Medicine \& Dentistry Lahore, Department of Physical Therapy, Main Raiwind \\ Road, Lahore
}

${ }^{2}$ Demonstrator, The University of Lahore, Department of Physical Therapy, Main Raiwind Road, Lahore

\begin{abstract}
Lumbago (LBP) is the most common spinal column problem worldwide. According to some roughly calculation almost 60$80 \%$ of the common population was suffer from LBP in their lifetime and 20-30\% affected from LBP at any specific time. It is cross sectional descriptive study in which 225 Medical students of Fatima Memorial Hospital College of Medicine \& Dentistry Lahore participated, the overall population was 995. Visual analogue scale and self administerd questionare were used as tool to collect the data in the duration of 3 months. It is calculated the data and observed that the male persons are (43.8\%) and females are (56.2\%). It is observed that the Lumbago is most common in females (33.5\%) as compared to males so result shows that Lumbago occurs mostly in the females of age 20 Years. This study was conducted to report the evidence on risk factors for Lumbago, particularly at the university level where these injuries are most common. In particular, gender difference, siting chair, family history, poor posture,wearing high heels, travelling on public transport, shoulder bag and prolonged sitting were important risk factors for Lumbago.
\end{abstract}

Keywords: Lumbago, Risk factors, physical features, Medicals, physical activities

\section{Introduction}

\subsection{Overview}

Lumbago (LBP) is the most common spinal column problem worldwide. According to some roughly calculation almost $60-80 \%$ of the common population was suffer from LBP in their lifetime and 20-30\% affected from LBP at any specific time. Cross-sectional data manifestation that early inception of Lumbago frequently appeared around the age of 20 to 60 years. LBP is not the disease of geriatrics. Unusually, $39.8 \%$ of the young community is also get experienced from LBP. It obstructs activates of routine life in young persons. LBP had been revealed as the dominant cause for specifying community actions.(1)

One sided LBP was a general issue among Youngsters seen by Therapists. As physical therapy cured of LBP is often conducted forward the vertebral facet joints or trunk curvature, neglected port ion of the disorder may involve joint problem within1 or both of the lower extremities. a general follow up is seen involve excessive 1 sided hip rotation and exaggerated subtler joint pronation on the equaling side as the one sided Lumbago.(2)

Causes for Lumbago had not been properly demonstrate. The major cause for Lumbago is vigorous physical work like move up, bad posture, and full body waving. Reason of LBP also Bad Life habits like Smoking, less physical b warm up and disturbed sleep enhance LBP. Relationship among LBP social and cognitive aspects included..(3)

Lumbago was very common in students, literature showed us many studied concluded all over the World on student had Lumbago.Inaisa this study was conducted in our nehibour country but never conducted in Pakistan.

\subsection{Objectives}

The objective of this study is to determine the prevalence and risk factors of Lumbago among the under graduates students of Fatima Memorial Hospital College of Medicine $\&$ Dentistry Lahore.

\subsection{Rationale}

The rationale of the study is to avoid the risk factors assoicated with Lumbago hence improving quality of student life.

\subsection{Operational Definitions}

Visual Analogue scale

The visual analog scale (VAS) is a scale used in surveys with a 9.3 Reliability and 9.4 Validity. It is a measurement instrument for particular features or approaches that cannot be directly measured. When responding to a VAS item, defendants identify their level of bargain to a statement by indicating a position between two end-points.

\subsection{Materials and methods}

\subsubsection{Study Design}

The present study is a cross sectional

\subsubsection{Setting}

The study was conducted in Fatima Memorial Hospital College of Medicine \& Dentistry Lahore.

\subsubsection{Study Population}

Male and Female students of Fatima Memorial Hospital College of Medicine \& Dentistry Lahore 


\section{International Journal of Science and Research (IJSR) \\ ISSN (Online): 2319-7064}

Index Copernicus Value (2013): 6.14 | Impact Factor (2015): 6.391

\subsubsection{Duration of Study}

The study took 4 months from November 2015 to February

2016 after approval from advance research committee

\subsubsection{Sample size}

The sample size was calculated by the following formula keeping the Margin of error is 5\%, Confidence level is $95 \%$, Total population size is 995 , Response distribution is $75 \%$ and Sample size is 224 .

$$
\begin{aligned}
x & =Z\left({ }^{c} / 100\right)^{2} r(100-r) \\
n & =N x / /_{\left((N-1) E^{2}+x\right)} \\
E & =\operatorname{Sqrt}\left[{ }^{(N-n) x} / n(N-1)\right]
\end{aligned}
$$

Where $\mathrm{N}$ is the population size, $\mathrm{r}$ is the fraction of responses that you are interested in, and $\mathrm{Z}(\mathrm{c} / 100)$ is the critical value for the confidence level c.

\subsubsection{Eligibility \\ Inclusion Criteria}

- Only medical students were selected in our sample.

- Students of age between 20-30 years.

E Exclusion Criteria

- Students having any past medical history or injury

- Students having any congenital disease.

- Students having any musculoskeletal injury during last 6 months

\subsubsection{Data collection}

The study was conducted in Fatima Memorial Hospital College of Medicine \& Dentistry Lahore which has about 224 students enrolled in MBBS at the start of study. 19 students refused to participate in the study and 13 were not available during study duration. Remaining 192 students were surveyed for VAS. 188 students were found to have Lumbago and remaining 36 were normal selected by simple random sampling using random number table who were matched in gender sitting chair, family history, poor posture, wearing high heels, travelling on public transport, shoulder bag and prolonged sitting. Visual Analogue Scale was used questionnaire with a reliability 9.3 and Validity 9.4.

\subsubsection{Ethical consideration}

The ethical committee and Department of Medical Education of Fatima Memorial Hospital College of Medicine \& Dentistry Lahore approved to conduct the study in College. Only those students were included in the study who signed the written consent. All the personal information of participants were kept hidden

\subsubsection{Statistical Procedure}

The Data was analyzed using SPSS v20.Mean \pm SD was calculated for numeric variables i.e. age and frequency and percentage was shown with categorical variables e.g. gender difference, sitting chair, family history, poor posture, wearing high heels, travelling on public transport, shoulder

\begin{tabular}{|c|c|c|c|}
\hline Variable & Construct & Frequency & Valid Percentage \\
\hline Frequency of pain & Pain & 188 & 84 \\
\hline$=$ & No pain & 36 & +2 \\
\hline Gender with Pain & Male & 78 & 66 \\
\hline+2 & $\begin{array}{c}\text { Female } \\
\end{array}$ & 110 & 93 \\
\hline Age in Years & $\begin{array}{r}20 \\
\end{array}$ & 1 & 0.4 \\
\hline & 2 & 75 & 33.5 \\
\hline & $\sqrt{2}$ & 47 & 21.0 \\
\hline 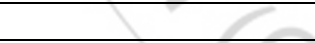 & $\gamma_{2}$ & 31 & 13.8 \\
\hline & \begin{tabular}{|l|l}
24 \\
\end{tabular} & 27 & 12.1 \\
\hline & $25 \square-5$ & 24 & 10.7 \\
\hline 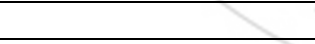 & \begin{tabular}{|r|}
$\quad 26$ \\
\end{tabular} & 14 & 6.3 \\
\hline & \begin{tabular}{|l|}
27 \\
\end{tabular} & 2 & 0.9 \\
\hline visual scale respondent & Valid - very mild pain & 36 & 16.1 \\
\hline & Normal mild pain & 10 & 4.5 \\
\hline & extreme mild pain & 53 & 23.7 \\
\hline & minor moderate pain & 48 & 21.4 \\
\hline & mild moderate pain & 12 & 5.4 \\
\hline & increasing moderate pain & 21 & 9.4 \\
\hline & high moderate pain & 1 & .4 \\
\hline & severe pain & 3 & 1.3 \\
\hline & worst pain possible & 5 & 2.2 \\
\hline place of sitting in class & chair with back support & 146 & 77.7 \\
\hline & chair without back support & 26 & 13.8 \\
\hline & any other & 14 & 7.4 \\
\hline lowback pain in parents & Father & 17 & 9.0 \\
\hline & Mother & 63 & 33.5 \\
\hline & Valid both & 30 & 16.0 \\
\hline & None & 78 & 41.5 \\
\hline Type of shoes & Heel & 63 & 33.5 \\
\hline & flat shoes & 46 & 24.5 \\
\hline & Joggers & 10 & 5.3 \\
\hline & Pump & 8 & 4.3 \\
\hline
\end{tabular}
bag and prolonged sitting.

\section{Results}

Volume 5 Issue 5, May 2016 www.ijsr.net 
International Journal of Science and Research (IJSR)

ISSN (Online): 2319-7064

Index Copernicus Value (2013): 6.14 | Impact Factor (2015): 6.391

\begin{tabular}{|c|c|c|c|}
\hline & any other & 61 & 32.4 \\
\hline \multirow[t]{5}{*}{ mode of transport from home to college } & public transport & 78 & 41.5 \\
\hline & Bike & 34 & 18.1 \\
\hline & Cycle & 12 & 6.4 \\
\hline & Valid car & 25 & 13.3 \\
\hline & Walking & 39 & 20.7 \\
\hline \multirow[t]{3}{*}{ load carry in shoulder bag } & $3 \mathrm{~kg}$ & 23 & 11.2 \\
\hline & less than $3 \mathrm{~kg}$ & 130 & 32.1 \\
\hline & greater then $3 \mathrm{~kg}$ & 35 & 55.6 \\
\hline \multirow[t]{4}{*}{ when pain increase } & prolong sitting & 72 & 38.3 \\
\hline & prolong standing & 65 & 34.6 \\
\hline & Walking & 28 & 14.9 \\
\hline & no change & 23 & 12.2 \\
\hline \multirow[t]{4}{*}{ types of bag use in daily routine } & one shoulder bag & 92 & 48.9 \\
\hline & two shoulder bag & 17 & 9.0 \\
\hline & hand carry bag & 30 & 16.0 \\
\hline & no bag & 49 & 26.1 \\
\hline \multirow[t]{4}{*}{ how you study } & sitting with back support & 103 & 54.8 \\
\hline & sitting without back support & 43 & 22.9 \\
\hline & Valid sitting on ground & 18 & 9.6 \\
\hline & Laying & 24 & 12.8 \\
\hline
\end{tabular}

There were majority of $188(84 \%)$ students which had a back pain and $36(16 \%)$ had no complain of back pain. The data was collected from 224 students in which 98 were males and 126 were females and it was observed that 78 males had back pain from 98 and 110 females respectively from 126 . There were a majority of $126(56.3 \%)$ females and 98 (43.8 $\%$ ) males respectively. A majority of $75(33.5 \%)$ students were of age 20 years, there were $47(21 \%)$ students of age 21 years, there were $31(13.8 \%)$ students of age 22 , there were $27(12 \%)$ students of age 23 , a lot of $24((10 \%)$. The people of age 20 to 30 mostly have normal mild pain and then minor moderate pain. The percentage of normal mild pain is 23.7 and minor moderate pain is 21.4. The percentage of high moderate pain, severe pain and worst pain is less seen in this age group. A Majority of the people sit on chair with back support and its percentage is 77.7 , so result shows that maybe people sit in bad posture with back support that cause back pain. Observation shows that family history does not matter in Lumbago because in most cases almost $41 \%$ people have back pain but their parents does not have back pain. But in most cases round about 33\% people it is observed that their mothers have back pain and they are also a patient of back pain.

Results shows that the females having back pain after wearing heels are $33.5 \%$ but there are some cases in which individuals wearing flat shoes also have back pain and the percentage is 24.5. The percentage of Lumbago in people wearing joggers and pump is less. It is observed that $41.5 \%$ people have back pain while travelling in public transport and then $18.1 \%$ people who rides bike have back pain. Result shows that $55.6 \%$ people who carries greater than 3 $\mathrm{kg}$ of shoulder bag have back pain but few cases also observed that individuals caries lesser than $3 \mathrm{~kg}$ of shoulder bag also have Lumbago but less in greater weight carries. Results shows that $38.3 \%$ people in prolong sitting it showed that it is also a causing factor of back pain but $34.6 \%$ individuals also have a complain of back pain so it means that both prolong sitting and standing is the causing factor of back pain. Results shows that almost $48.9 \%$ individuals use one shoulder back having a complaint of back pain so it may be the causing factor of Lumbago. But there are many cases in which individual doesn't uses shoulder bags but also have a complaint of back pain.

Result shows that majority of the students who study sitting with back support have a complain of back pain and they are 54.8 percent. The people having back pain who study without back support have are less in percentage. It is observed that the Lumbago increases when you sit on chair and the percentage is 44.7.the persons having back pain who walk are less in number and the percentage is 21.3 .

\section{Conclusion}

This study was conducted to report the evidence on risk factors for Lumbago, particularly at the university level where Lumbago is most common. Overall, the study identified a number of potential causal relations between baseline factors and Lumbago. In particular, if we talk about gender then it is most common in females as compared to males and those students who use sitting chair with back support had a high ratio of back pain due to bad posture of sitting., Although family history matters, because mostly students had back majority had a family history. Wearing high heels was one of the most common risk factors in females ,the travelling was also risk factors of back pain and it was most commonly seen in public transport users, the weight carrying via shoulder bag and prolonged sitting were important risk factors for Lumbago., This study was help for finding the risk factors and prevalence of Lumbago in Medical students. In this the students was able to avoid those risk factors hence improving quality of student life. We can further extend this study to next level by conducting interventional studies.

\section{References}

[1] Aggarwal N, Anand T, Kishore J, Ingle GK. Lumbago and associated risk factors among Medical students of a medical college in Delhi. Education for Health. 2013;26(2):103. 


\section{International Journal of Science and Research (IJSR) \\ ISSN (Online): 2319-7064 \\ Index Copernicus Value (2013): 6.14 | Impact Factor (2015): 6.391}

[2] Cibulka MT. Lumbago and its relation to the hip and foot. Journal of Orthopaedic \& Sports Physical Therapy. 1999;29(10):595-601.

[3] Tomita S, Arphorn S, Muto T, Koetkhlai K, Naing SS, Chaikittiporn C. Prevalence and risk factors of Lumbago among Thai and Myanmar migrant seafood processing factory workers in Samut Sakorn Province, Thailand. Industrial health. 2010;48(3):283-91.

[4] Jones G, Macfarlane G. Epidemiology of Lumbago in children and adolescents. Archives of disease in childhood. 2005;90(3):312-6.

[5] Wirth B, Knecht C, Humphreys K. Spine day 2012: spinal pain in Swiss school children-epidemiology and risk factors. BMC pediatrics. 2013;13(1):159.

[6] Hill JJ, Keating JL. Risk factors for the first episode of Lumbago in children are infrequently validated across samples and conditions: a systematic review. Journal of physiotherapy. 2010;56(4):237-44.

[7] Nourbakhsh MR, Arab AM. Relationship between mechanical factors and incidence of Lumbago. J. of Orthopaedic \& Sports Physical Therapy. 2002;32(9):447-60.

[8] Gill C, Sanford J, Binkley J, Stratford P, Finch E. Lumbago: program description and outcome in a case series. J. of Orthopaedic \& Sports Physical Therapy. 1994;20(1):11-6.

[9] Wirth B, Humphreys BK. Pain characteristics of adolescent spinal pain. BMC pediatrics. 2015;15(1):42.

[10]Leboeuf-Yde C, Fejer R, Nielsen J, Kyvik KO, Hartvigsen J. Pain in the three spinal regions: the same disorder? Data from a population-based sample of 34,902 Danish adults. Chiropractic \& manual therapies. 2012;20(1):11.

[11] Clifford SN, Fritz JM. Children and adolescents with Lumbago: a descriptive study of physical examination and outcome measurement. J. of Orthopaedic \& Sports Physical Therapy. 2003;33(9):513-22.

[12] Feldman DE, Shrier I, Rossignol M, Abenhaim L. Risk factors for the development of Lumbago in adolescence. American Journal of Epidemiology. 2001;154(1):30-6.

[13] Frymoyer J, Pope M, Clements JH, Wilder DG, MacPherson B, Ashikaga T. Risk factors in low-back pain. An epidemiological survey. The J. of bone and joint surgery American volume. 1983;65(2):213-8.

[14] Yue P, Liu F, Li L. Neck/shoulder pain and Lumbago among school teachers in China, prevalence and risk factors. BMC Public health. 2012;12(1):789.

[15] Heuch I, Heuch I, Hagen K, Zwart J-A. Body mass index as a risk factor for developing chronic Lumbago: a follow-up in the Nord-Trøndelag Health Study. Spine. 2013;38(2):133-9.

[16] Harreby M, Nygaard B, Jessen T, Larsen E, StorrPaulsen A, Lindahl A, et al. Risk factors for Lumbago in a cohort of 1389 Danish school children: an epidemiologic study. European Spine Journal. 1999;8(6):444-50.

[17] Hartvigsen J, Davidsen M, Hestbaek L, Sogaard K, Roos EM. Patterns of musculoskeletal pain in the population: A latent class analysis using a nationally representative interviewer-based survey of 4817 Danes. European J. of Pain. 2013;17(3):452-60.

[18] Kim MH, Chung HY, Yoo WG, Choi BR. EMG and kinematics analysis of the trunk and lower extremity during the sit-to-stand task while wearing shoes with different heel heights in healthy young women. Human movement science. 2011;30(3):596-605.

[19] Sheir-Neiss GI, Kruse RW, Rahman T, Jacobson LP, Pelli JA. The association of backpack use and back pain in adolescents. Spine. 2003;28(9):922-30.

[20] Beach TA, Parkinson RJ, Stothart JP, Callaghan JP. Effects of prolonged sitting on the passive flexion stiffness of the in vivo lumbar spine. The Spine J. 2005;5(2):145-54.

\section{Author Profile}

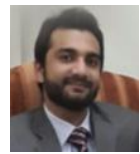

Fahad Tanveer is Senior Lecturer, Azra Naheed Medical College, Department of Physical Therapy, Main Raiwind Road, Lahore

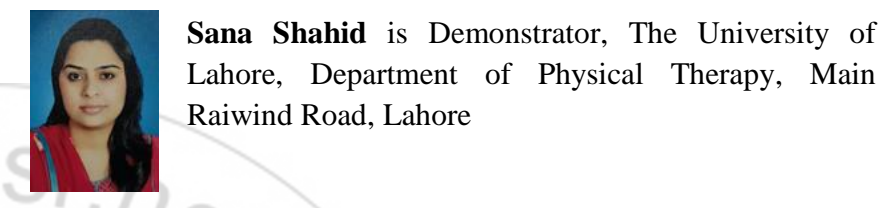

